\title{
The level and potential determinants of the adherence to the antiretroviral therapy among patients on HIV treatment in gemena referral hospital, South Ubangi, Democratic Republic of Congo, 2018
}

\begin{abstract}
Introduction: Suboptimal adherence to antiretroviral therapy (ART) is a major hinderance to achieving the 909090 goals in limited resources settings. South Ubangi province in DR Congo faces countless challenges providing universal HIV care. However, the level of ART adherence and associated factors among people on HIV treatment in this province remains unknown. Using a quantitative method approach, this study aimed to know the extend of adherence and to identify the determinants of optimal and suboptimal adherence among study participants.
\end{abstract}

Methods: A cross-sectional research design was used to survey patients on ART in Gemena Referral Hospital.

Results: After a simple randomly sampling from a sampling frame of 503 patients on treatment and who met the inclusion criteria of been using HIV treatment for at least one year, 438 were selected taking the even numbers in three rounds, but only 398 patients consented to participate to the study. Logistic regression was run to explore determinants of the adherence. The participants mean age was 42 years old (range: 8-62 years old). 280 participants were Female $(=70.4 \%)$ and 118 were male $(29.6 \%)$ with a sex ratio Female-male of 2.4/1. Most of the participants were married 185(46.5\%), 45 were divorced $(=1.3 \%), 136$ widow/widowers $(34.2 \%$ made up of 116 widowers $=29 \%$ and 20 widows $=4.2 \%$ ) and only 32 were unmarried $(8 \%)$. Among the married, 117 had only one partner ( $29 \%$ of overall), 42 had more than one partner $(11 \%)$ and 26 were in a mere cohabitation (6.5\%). ART adherence was $77 \%$ in the study population, while it should reach the optimal level of $95 \%$. Adherence was positively associated with age, but suboptimal adherence was significantly associated with forget to take the drugs, distance, the degree of contentment to the family support, and moving out of home. Adherence was likely associated with age, in fact, old participants(44-60 age group) had 8.3 times an increased probability of being adherent $(2.30-8.84,95 \% \mathrm{CI}$, p-value $=0.001)$ compared to $8-25$ age group. Additionally, taking his pills on daily basis had 1.68 times an increased probability of optimal adherence $(1.39-1.98,95 \% \mathrm{CI}$, p-value $<0.001)$, compared to those patients who sometimes forget to take their pills. Distance $<$ or $=5 \mathrm{~km}$ also had 2.47 an increased probability of being adherent (2.06-2.87, p-value $<0.001)$ compared to people who live beyond $5 \mathrm{~km}$ from the health facility. Participants who stated they had a high degree of contentment to family support presented 1.93 times an increased probability of being adherent $(1.93-1.46,95 \%$ CI, $p$-value $=0.001)$ compared with those with low degree of contentment to the family support. Participants who were resident had 1.55
Volume 10 Issue 3 - 2020

\author{
Charles Kombi K,' Jerome Mastaki K,' \\ Antoinette Tshefu K, ${ }^{3}$ Micheline Fatuma, ${ }^{4}$ \\ Herve Nzereka $K^{5}$ \\ 'Community Health, Kinshasa School of Public health, \\ Democratic Republic of the Congo \\ 2Social Epidemiology, University of Goma, Democratic Republic \\ of the Congo \\ ${ }^{3}$ Community Health, Kinshasa School of Public Health, \\ Democratic Republic of the Congo \\ ${ }^{4}$ Department of Biostatics, University of Washington School of \\ Public Health/ Kinshasa School of Public Health, Democratic \\ Republic of the Congo \\ ${ }^{5}$ Master of Philosophy, Swaziland
}

\begin{abstract}
Correspondence: Charles Kombi K, Community Health, University of Kinshasa School of Public health, Democratic Republic of the Congo,Tel +24382I533765,
\end{abstract}

Email charles0Ikombi@gmail.com

Received: June 08, 2020 | Published: June 22, 2020

times an increased significant probability to be adherent $(1.28-1.82,95 \% \mathrm{CI}$, p-value $<0.001$ ), compared to those who temporarily/definitely moved out their home for any reason. Gender, marital status, and monthly income did not have a significant association with adherence to antiretroviral therapy among people surveyed in the study.

Conclusion: Suboptimal adherence is still a serious issue among ARVs users in resource limited settings. Further strategies to boost adherence to the optimal level and beyond would imply to increase personal capacities to adhere to therapy instructions, lessen stigma and discrimination barriers by the proxy and within patients' families and foster the implication of the family members and the community in therapy, promote drugs provisions at home and differentiated health care management, etc.

Keywords: antiretroviral therapy, adherence, HIV treatment, antiretroviral therapy

\section{Introduction}

Adherence to the antiretroviral therapy is crucial to reach the 9090 90 objectives operationalized in South Ubangi province. While HIV was still making victims in the semi and rural areas in this province, availability and accessibility to HIV services have been made possible with the assistance of the global community and different stakeholders. The national response to this epidemic has consisted in setting a coordination to evolve standards and operational plans to manage the epidemic. Gemena referral Hospital covered an estimated total population of 347029 people in 2018. From the national statistics, the proportion of people whose HIV+ status is known is $1.03 \%$. Therefore the expected number of HIV patients in Gemena Referral Hospital should be 3574 patients. The known number of Persons living with HIV was 1252 patients, among the former, 1080 were taking the ARVs drugs in 2018. Among the former, 27 patients were reported dead and 16 lost to follow up, while 8 were taking the second line of ARVs. Unfortunately to our knowledge, no previous 
study in the context was made to reliably document the extend of and factors associated with adherence among people using ARV services in this facility. Adherence is described as the engagement and accurate participation of an informed patient in a plan of care. ${ }^{1}$ The concept of 'adherence' has a broader meaning than compliance. It encompasses the extent to which a patient follows instructions and implies understanding, consent and partnership through a continuing care plan. ${ }^{2-7}$

The relative accuracy of adherence measures ranks from physician assessment and self-assessment being the least accurate, by pill counting being intermediate, and Electronic Monitoring being the most accurate. ${ }^{2}$ The use of more than one measure of adherence allows the strengths of one method to compensate for the weakness of the other and to more accurately capture the information needed to determine adherence level. ${ }^{7}$ For the purposes of this study, 'Near perfect adherence' was defined as 95\% and above adherence. Patients whose Electronic Monitoring data indicated high adherence (above $90 \%$ ) were far more likely to achieve undetectable viral load than patients' self-reporting the same level of adherence. The advantageous maintenance of viral suppression requires maximum adherence (at least $95 \%$ ) to ART. ${ }^{5}$ But suboptimal adherence in such environment would subsequently be a probable factor of HIV transmission and higher cumulative incidence of HIV among the population, the therapy shift, and rise in the incidence of HIV mortality. Therefore studying adherence to antiretroviral therapy among patients on HIV treatment in Gemena referral Hospital would be an important step to assess the way patients manage individually and responsibly their status toward the ART service available to them, but also determine factors of optimal and suboptimal adherence to the ART.

\section{Objectives}

To know the extend of adherence and to identify the factors of optimal and suboptimal adherence among the study participants.

\section{Methods}

This study was carried out in Gemena referral hospital. The health facility is endeavoured with complementary health care packages, which also includes HIV services. Unfortunately, the health facility is not able to perform neither the CD4 count nor viral load tests. This constituted a limit to conduct biological assessment of adherence among study participants. This study used a cross-sectional study approach using interviews among the study participants. To be selected for this study, potential participants should meet following criteria: use of Gemena referral hospital ARV services, taking ART for at least one year and consent to participate to the study. Therefore, 503 patients routinely came to the facility for drugs provision in one month study period were alphabetically listed from 1 to 503, and who meet at least one year of being on HIV treatment criterion. Then, the even numbers for the first round were selected. The unselected were re-listed and the second round was runned and the third rounds to take the evens. We found 438 patients eligible to the study, but 398 participants consented to participate in the study, while the remaining 40 did not consent. These participants were interviewed at same day as they came on the monthly appointment for drugs' provision.

\section{Results}

Data were processed and analyzed in Stata 13 for Windows. Adherence variable was generated by combining Typederegime $==1 \&$
Sauttraitement $=0$ \& Frequencedinterruption $==0$. It was tabulated to find a binary outcome variable adherence $=1$ and nonadherence $=0$. In the same way, some predictors were generated from raw variables to make easy analysis, such as age categorised in agrp, social economic status in SSEC, and marital status in Mstatus. Then, we tabulated row/ generated predictor variables with the outcome to find the proportion of adherence among patients who presented mentioned characteristics Table 1, as well as their possible association with the outcome (Table 2). Moreover, logistic regression was runned to explore the determinants of the adherence (Table 3). The mean age was 42 years old (range: 8-62 years old).Most of the participants were $280(=70.4 \%)$ while male were $118(29.6 \%)$ with a sex ratio Female-male of 2.4/1. 185 participants were married $(46.5 \%), 45$ were divorced $(=1.3 \%), 136$ widow/ widowers $(34.2 \%$ with 116 widowers $=29 \%$ and 20 widows $=4.2 \%)$ and only 32 were unmarried (8\%). Among the married, 117 had only one partner $(29 \%$ of overall), 42 had more than one partner $(11 \%)$ and 26 were a mere cohabitation (6.5\%). ART adherence level was $77 \%$ in the study population, while it should reach the optimal level of $95 \%$. Adherence was positively associated with age and the degree of contentment to the family support but suboptimal adherence was also associated with forget to take the drugs, distance and moving out of home. Adherence was positively associated with age, in fact, old participants(44-60 age group) had 8.3 times an increased probability of being adherent ( 2.30-8.84, 95\% CI, p-value $<0.001)$, compared to 8-25 age group. Additionally, having taken his pills on the daily basis had 1.68 times an increased significant probability of optimal adherence $(1.39-1.98,95 \% \mathrm{CI}$, p-value $<0.001)$, compared to those patients who sometimes forgot to take their pills. Distance $<$ or $=5$ $\mathrm{km}$ also had 2.47 times an increased probability of being adherent $(2.06-2.8795 \% \mathrm{CI}, \mathrm{p}$-value $<0.001)$ compared with people who lived beyond $5 \mathrm{~km}$ from the Health facility. Participants who stated they had a high degree of contentment to family support presented 1.93 times an increased probability of being adherent (1.93-1.46, 95\% CI, $\mathrm{p}$-value $=0.001)$ compared with those with low degree of contentment to the family support Participants who were resident had 1.55 times an increased significant probability to be adherent $(1.28-1.82,95 \% \mathrm{CI}$, p-value $<0.001)$, compared with those who moved out their home for any reason and lost to follow up. Gender, monthly income and marital status did not have a significant association with the adherence to the antiretroviral therapy among in the study population (Figures 1\&2).

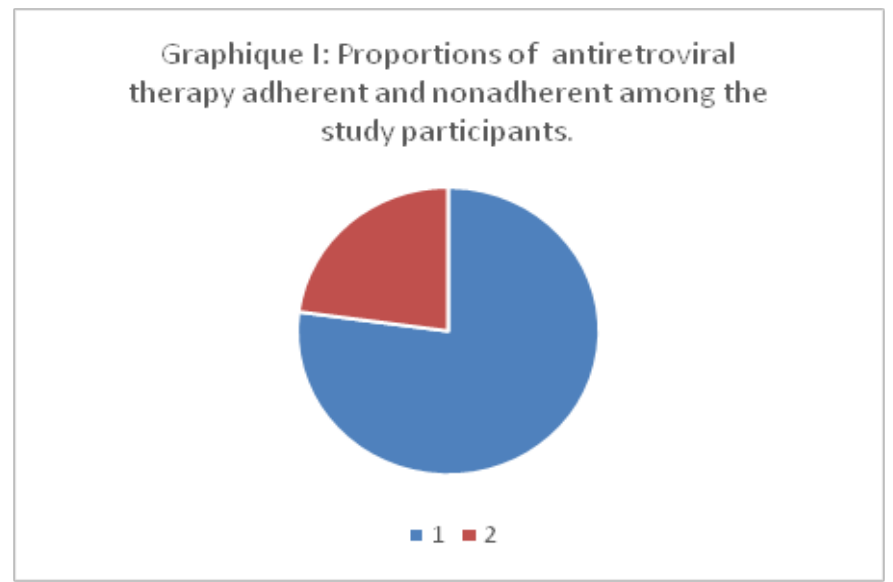

Figure I I=adherent (77\%), 2= non adherent (23\%). 
Table I Demographic characteristics of participants using HIV/Antiretroviral services in Gemena referral hospital in May, 2017

\begin{tabular}{|c|c|c|}
\hline & \multicolumn{2}{|l|}{ Adherence } \\
\hline & $\begin{array}{l}\text { Ad } \\
\text { N (\%) }\end{array}$ & Non-Ad \\
\hline Overall & $307(77,14)$ & 9ㅣㅣ(22,86) \\
\hline \multicolumn{3}{|l|}{ Gender } \\
\hline Male & $96(42,12)$ & $22(5,52)$ \\
\hline Female & $211(53.01)$ & $69(15.57)$ \\
\hline \multicolumn{3}{|l|}{ Age in years } \\
\hline $8-25$ & $5(1.25)$ & $6(1.50)$ \\
\hline $26-43$ & $144(36.18)$ & $62(15.57)$ \\
\hline $44-60$ & 156(39.19) & $22(5.53)$ \\
\hline $60+$ & $2(0.5)$ & $\mathrm{I}(0.2)$ \\
\hline \multicolumn{3}{|l|}{ Ssec } \\
\hline Low & $301(75.63)$ & $91(22.86)$ \\
\hline Acceptable & $6(1.51)$ & $0(0)$ \\
\hline \multicolumn{3}{|l|}{ Distance } \\
\hline Near & $303(76.13)$ & $66(15.58)$ \\
\hline Far & $4(1)$ & $25(1)$ \\
\hline \multicolumn{3}{|l|}{ Forget } \\
\hline 0 & 295(7I.I2) & $55(\mid 3.81)$ \\
\hline I & $12(3.0)$ & $36(9.0)$ \\
\hline \multicolumn{3}{|l|}{ Transfees } \\
\hline 0 & $304(76.38)$ & $36(9.04)$ \\
\hline I & $3(0.7)$ & $55(\mid 3.81)$ \\
\hline \multicolumn{3}{|c|}{$\begin{array}{l}\text { Degree of contentment to } \\
\text { family support }\end{array}$} \\
\hline 0 & $48(31.87)$ & $28(15.64)$ \\
\hline I & $62(68.13)$ & $259(84.36)$ \\
\hline \multicolumn{3}{|l|}{ Move } \\
\hline 0 & $302(75.88)$ & $64(16.08)$ \\
\hline I & $5(12.56)$ & $27(6.78)$ \\
\hline \multicolumn{3}{|l|}{ Mstatus } \\
\hline I & $30(7.5)$ & $2(0.5)$ \\
\hline 2 & $78(19.6)$ & $39(8.0)$ \\
\hline 3 & $28(7.0)$ & I $4(3.5)$ \\
\hline 4 & $26(6.5)$ & $0(0.0)$ \\
\hline 5 & $34(8.5)$ & II(2.8) \\
\hline 6 & III(28.0) & $25(2.3)$ \\
\hline
\end{tabular}

Citation: Charles KK, Jerome MK,Antoinette TK, et al. The level and potential determinants of the adherence to the antiretroviral therapy among patients on HIV treatment in gemena referral hospital, South Ubangi, Democratic Republic of Congo, 20 I8.J Pediatr Neonatal Care. 2020; I0(3):79-84. DOI: 10.15406/jpnc.2020.10.00416 
Table 2 Calculated adherence and possible association with some predictors among study participants

\begin{tabular}{|c|c|c|c|c|c|}
\hline & $\begin{array}{l}\text { Ad } \\
\mathbf{N}(\%)\end{array}$ & $\begin{array}{l}\text { Non-ad } \\
\text { N (\%) }\end{array}$ & $\begin{array}{l}\text { Chi- } \\
\text { squarred }\end{array}$ & P value & $\begin{array}{l}95 \% \\
\text { C.I }\end{array}$ \\
\hline Overall & $307(77,14)$ & $91(22,86)$ & & & \\
\hline \multicolumn{6}{|l|}{ Gender } \\
\hline Male & $96(42,12)$ & $22(5,52)$ & 1.69 & 0.193 & \\
\hline Female & $211(53.01)$ & $69(15.57)$ & & & \\
\hline \multicolumn{6}{|c|}{ Age in years } \\
\hline $8-25$ & $5(1.25)$ & $6(1.50)$ & & & \\
\hline $26-43$ & $144(36.18)$ & $62(15.57)$ & & & \\
\hline $44-60$ & $156(39.19)$ & $22(5.53)$ & 23.53 & 0.000 & \\
\hline $60+$ & $2(0.5)$ & $\mathrm{I}(0.2)$ & & & \\
\hline \multicolumn{6}{|l|}{ Ssec } \\
\hline Low & $30 \mathrm{I}(75.63)$ & $91(22.86)$ & 1.81 & 0.000 & \\
\hline Acceptable & $6(1.51)$ & $0(0)$ & & & \\
\hline \multicolumn{6}{|l|}{ Distance } \\
\hline Near & $307(76.13)$ & $26(06.53)$ & 262.08 & 0.000 & \\
\hline Far & $0(0.00)$ & $65(16.33)$ & & & \\
\hline \multicolumn{6}{|l|}{ Forget } \\
\hline 0 & 295(7I.12) & $55(|3.8|)$ & & & \\
\hline I & $12(3.0)$ & $36(9.0)$ & 84.12 & 0.000 & \\
\hline \multicolumn{6}{|l|}{ Transfees } \\
\hline 0 & $304(76.38)$ & $36(9.04)$ & 199.36 & 0.000 & \\
\hline I & $3(0.7)$ & $55(|3.8|)$ & & & \\
\hline \multicolumn{6}{|c|}{$\begin{array}{l}\text { Degree of } \\
\text { contentment to } \\
\text { family support }\end{array}$} \\
\hline 0 & $48(31.87)$ & $29(15.64)$ & 11.53 & 0.001 & \\
\hline I & $62(68.13)$ & $259(84.36)$ & & & \\
\hline \multicolumn{6}{|l|}{ Move } \\
\hline 0 & $302(75.88)$ & $64(16.08)$ & & & \\
\hline I & $5(12.56)$ & $27(6.78)$ & 74.65 & 0.000 & \\
\hline \multicolumn{6}{|l|}{ Mstatus } \\
\hline I & $30(7.5)$ & $2(0.5)$ & & & \\
\hline 2 & $78(19.6)$ & $39(8.0)$ & & & \\
\hline 3 & $28(7.0)$ & $14(3.5)$ & & & \\
\hline 4 & $26(6.5)$ & $0(0.0)$ & & & \\
\hline 5 & $34(8.5)$ & $\mathrm{II}(2.8)$ & & & \\
\hline 6 & III(28.0) & $25(2.3)$ & & & \\
\hline
\end{tabular}

Citation: Charles KK, Jerome MK, Antoinette TK, et al. The level and potential determinants of the adherence to the antiretroviral therapy among patients on HIV treatment in gemena referral hospital, South Ubangi, Democratic Republic of Congo, 20 18.J Pediatr Neonatal Care. 2020; 10(3):79-84. DOI: 10.15406/jpnc.2020.10.00416 
Table 3 Potential determinants of optimal and suboptimal adherence among participants, using logistic regression

\begin{tabular}{|c|c|c|c|c|c|}
\hline & $\begin{array}{l}\text { Adherence } \\
\text { Ad } \\
\text { N (\%) }\end{array}$ & $\begin{array}{l}\text { Non-ad } \\
\text { N (\%) }\end{array}$ & $\begin{array}{l}\text { Logistic } \\
\text { Regression }\end{array}$ & $\begin{array}{l}\text { Confidence } \\
\text { Interval }\end{array}$ & $P$ value \\
\hline Overall & $307(77, \mid 4)$ & $91(22,86)$ & & & \\
\hline \multicolumn{6}{|l|}{ Gender } \\
\hline Male & $96(42,12)$ & $22(5,52)$ & 4.36 & $2.74-6.93$ & 0.94 \\
\hline Female & $21 I(53.01)$ & $69(15.57)$ & & & \\
\hline \multicolumn{6}{|l|}{ Age in years } \\
\hline $8-25$ & $5(1.25)$ & $6(1.50)$ & & & \\
\hline $26-43$ & $144(36.18)$ & $62(15.57)$ & & & \\
\hline $44-60$ & $156(39.19)$ & $22(5.53)$ & 8.3 & $2.30-8.84$ & 0.001 \\
\hline $60+$ & $2(0.5)$ & $\mathrm{I}(0.2)$ & & & 0.522 \\
\hline \multicolumn{6}{|l|}{ Ssec } \\
\hline Low & $301(75.63)$ & $91(22.86)$ & 1.19 & $0.96-1.43$ & 0.000 \\
\hline Acceptable & $6(I .5 \mathrm{I})$ & $0(0)$ & & & \\
\hline \multicolumn{6}{|l|}{ Distance } \\
\hline Near & $303(76.13)$ & $66(15.58)$ & 2.47 & $2.06-2.87$ & 0.000 \\
\hline Far & $4(1)$ & $25(1)$ & & & \\
\hline \multicolumn{6}{|l|}{ Forget } \\
\hline 0 & 295(7I.12) & $55(|3.8|)$ & 1.68 & $1.39-1.98$ & 0.000 \\
\hline I & $12(3.0)$ & $36(9.0)$ & & & \\
\hline \multicolumn{6}{|c|}{ Lab test Affordability } \\
\hline 0 & $303(76.13)$ & $32(8.0)$ & 2.25 & $|.88-2.6|$ & 0.000 \\
\hline I & $4(1.0)$ & $59(14.82)$ & & & \\
\hline \multicolumn{6}{|l|}{ Transfees } \\
\hline 0 & $304(76.38)$ & $36(9.04)$ & & & \\
\hline I & $3(0.7)$ & $55(\mid 3.81)$ & 1.23 & I.79-2.48 & 0.000 \\
\hline \multicolumn{6}{|c|}{$\begin{array}{l}\text { Degree of contentment to } \\
\text { Family support }\end{array}$} \\
\hline 0 & $48(31.87)$ & $29(15.64)$ & & & \\
\hline I & $62(68.13)$ & $259(84.36)$ & 1.93 & I.39-I.46 & 0.001 \\
\hline \multicolumn{6}{|l|}{ Move } \\
\hline 0 & $302(75.88)$ & $64(16.08)$ & $\mathrm{I} .55$ & I.28-I.82 & 0.000 \\
\hline I & $5(12.56)$ & $27(7.78)$ & & & \\
\hline \multicolumn{6}{|l|}{ Mstatus } \\
\hline I & $30(7.5)$ & $2(0.5)$ & & & \\
\hline 2 & $78(19.6)$ & $39(8.0)$ & & & \\
\hline 3 & $28(7.0)$ & I4(3.5) & & & \\
\hline 4 & $26(6.5)$ & $0(0.0)$ & & & \\
\hline 5 & $34(8.5)$ & II(2.8) & & & \\
\hline 6 & || $\mid(28.0)$ & $25(2.3)$ & 0.1 & $-0.25-0.22$ & 0.118 \\
\hline
\end{tabular}

Citation: Charles KK, Jerome MK, Antoinette TK, et al. The level and potential determinants of the adherence to the antiretroviral therapy among patients on HIV treatment in gemena referral hospital, South Ubangi, Democratic Republic of Congo, 2018.J Pediatr Neonatal Care. 2020; I0(3):79-84. DOI: 10.15406/jpnc.2020.10.00416 
Graph. III: The distribution of the adherence by gender among the study participants

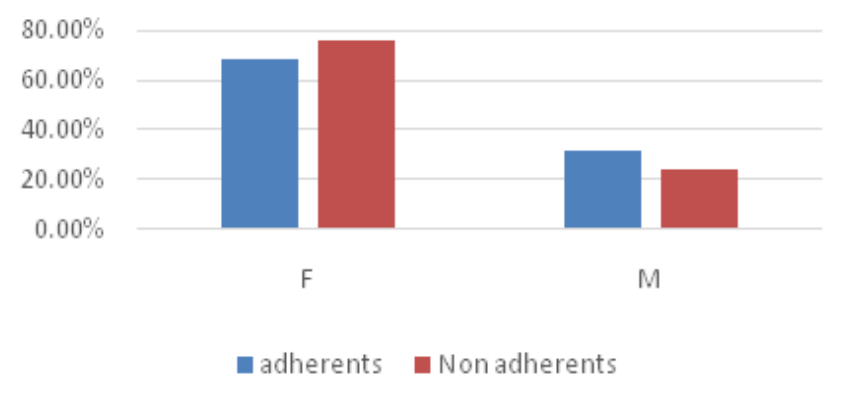

Figure 2 blue=adherent, red=nonadherent.

\section{Discussion}

Patients' age had the likelihood to be significantly associated with adherence to ART. In fact, getting older was associated with an increase in the probability to be adherent to the therapy. This is supported with a study by Scott E. et al in 2012 who found that despite the absence of financial barriers, younger injection drugs users remain less likely to adhere to ART, this subsequently which would result in inferior viral load suppression. ${ }^{6}$ Therefore, the incidence of $\mathrm{HIV}$ in the community would remain high, given the young people sexual behavior. ${ }^{6}$ A predictor of suboptimal adherence in the study population was the geographical accessibility to the ARV drugs services. In addition to the psychological effect of the HIV status and therapy, patients living far from health facility were less likely to adhere to the therapy, this is true in a context of low income with no public transportation. Forgetting to take drugs also showed a significant association with low adherence to the therapy. In fact, the ability to consistently take medicines at exactly or approximately the same times each day depends on the individual mind state as well as the support from the family members, and people around the patients. ${ }^{1}$ This imposes constraints on the daily schedule and lifestyle and it can sometimes be difficult for individuals to adapt to these demands, especially on a long-term run. Adherence is therefore best thought of as a modifiable variable behaviour rather than as a constant characteristic of an individual. Most people will exhibit low adherence at one point or another. ${ }^{2}$ It is assumed that immediate family members would play an important role to support the adherence, by recalling drugs instructions and help the patient handle positively the general health conditions. In fact in the study population, patients with higher degree of contentment to family support showed an optimal adherence compared with those with low degree of contentment. Furthermore, patients who moved out of their residency and those lost to follow up had a strong likelihood of suboptimal adherence to the therapy, compared with residents.
However, adherence did not greatly increase with the economic status. There is often a false tendency to ascribe low adherence to (often deprived) social groups as well-established in the general literature, dating back to 1990 when tuberculosis control occupied public health officials. ${ }^{4}$ But, since the antibiotics generation, adherence among patients in developed countries did not significantly differ from that of patients in developing countries. ${ }^{4}$ The same false tendency goes for marital status and gender, rather these factors are found in the literature to be likely associated with the HIV transmission.

\section{Conclusion}

The pilot study findings demonstrate there are predictors we should act on in order to reach the optimal adherence to the ART among the study population, mainly those which showed likelihood of significant association with the optimal and suboptimal adherence. Further strategies to boost the adherence to the optimal level and beyond would imply to strengthen personal capacities to adhere to therapy instructions, lessen stigma and discrimination barriers by the community and patients'families implication in the therapy and promote drugs provisions at home and differentiated health care management, etc.

\section{Acknowledgments}

None.

\section{Conflicts of interest}

The authors declare there are no conflicts of interest.

\section{Funding}

None.

\section{References}

1. Anita Hardon. From access to adherence: the challenges of the antiretroviral treatment, 2009.

2. Horne. Predicting Treatment adherence: An overview of theoretical models, In Myers LB, Midence K, editors, 1998.

3. Kokolomami Jacques. Draft of adherence protocol, Kinshasa School of Public health, 2009.

4. Lerner. Tuberculosis Then and Now: perspectives on the history of an infectious disease, Baltimore: Johns Hopkins University Press; 1998.

5. Paredes. Predictor of virological success and ensuring failure in HIVPositive patients starting highly active retroviral therapy in Europe: results from Eurosida study. Pubmed. 2000; 160(8):1123-32.

6. Scott. Entry Into en Retention in HIV Medical care. Annals of Internal Medicine. 2012;156(11).

7. Vitolins M Z. Measuring adherence to behavioural and medical interventions. Pubmed. 2000;21(5 Suppl):188S-94S. 